\title{
The current landscape of urological undergraduate education in Canada
}

Trustin Domes ${ }^{1}$; Samya Vellani ${ }^{1}$; Félix Couture ${ }^{2}$; Naeem Bhojani ${ }^{3}$; Sero Andonian ${ }^{4}$; Salima Ismail $^{5}$; Keith Rourke ${ }^{6}$; Dawn MacLellan ${ }^{7}$

${ }^{1}$ University of Saskatchewan, Saskatoon, SK, Canada; ${ }^{2}$ Centre hospitalier universitaire de Québec, Quebec City, QC, Canada; ${ }^{3}$ Centre hospitalier de l'Université de Montréal, Montreal, QC, Canada; ${ }^{4}$ McGill University, Montreal, QC, Canada; ${ }^{5}$ Université Sherbrooke, Sherbrooke, QC, Canada; ${ }^{6}$ Uinversity of Alberta, Edmonton, AB, Canada; ${ }^{7}$ Dalhousie University, Halifax, NS, Canada

Cite as: Can Urol Assoc J 2020 June 5; Epub ahead of print. http://dx.doi.org/10.5489/cuaj.6424

Published online June 5, 2020

$* * *$

\begin{abstract}
Introduction: Urological presentations are commonly seen in primary care and urologists are concerned that educational gaps exist in undergraduate curricula in Canadian medical schools. A pan-Canadian survey of undergraduate urology education directors (UUEDs) was used to determine the current status of undergraduate urology education in Canada.

Methods: In the fall of 2018, a survey was administered to all 17 UUEDs representing every Canadian medical school. The survey assessed multiple factors, including the timing and duration of urologist-led instruction, the perceived adequacy of urological content in the curriculum, and the level of preparedness of graduating students.
\end{abstract}

Results: The response rate was $100 \%$. Variation in the duration (mean total instructional hours: $22.5 \pm 17.2$ [5-75] hours) and timing of formal urological instruction was seen. The majority of schools covered core content areas, however, erectile dysfunction, uro-trauma, and pediatric urology topics were under-represented. One school had a mandatory urology clerkship rotation (one week), while the other 16 schools offered a selective, with $24.3 \%$ of students completing this experience. The majority of UUEDs $(64.7 \%)$ believed the curricular time devoted to urology was inadequate, $29.4 \%$ felt that their graduates were unprepared to diagnose and treat common urological problems, and $76.5 \%$ strongly agreed or agreed that a national urology curriculum would be useful.

Conclusions: There was significant variability in the duration of instruction and delivery of urological topics in Canadian medical schools. There was a perceived need for more urological instruction by most UUEDs, who welcomed a more standardized national curriculum as a strategy to address this need. 


\section{Introduction}

Although curriculum design and delivery varies between medical schools, there is an expectation and assumption that all Canadian medical schools cover core medical content to a similar degree. Unfortunately, there is limited data available to compare the different Canadian medical schools on the quality and quantity of instruction in the formal curricula, including for urology. In the United States there has been a steady decline in undergraduate urological education since the $1950 \mathrm{~s}^{1}$, with studies demonstrating marked variability in total instructional time and clinical exposure in medical school. ${ }^{1,2,3}$ It is presumed that the Canadian trajectory is similar to the American experience. Given this decline, students have less exposure to urology, potentially leading to gaps in their medical expert knowledge, clinical skills and comfort in dealing with patients presenting with urological conditions. ${ }^{1,4,5}$ Decreasing urology exposure in the undergraduate curriculum may negatively impact the quality and appropriateness of referrals to urologists, leading to higher health care costs and wait times for specialist consultation. ${ }^{2}$ Additionally, Kin and colleagues have shown that in the Canadian context exposure to urology was the most important factor associated with medical student's positive perception of the specialty, which plays a role in student recruitment to the field and dispelling misperceptions of the specialty. ${ }^{6}$

Given the aging Canadian population and high prevalence of urological conditions presenting to primary care physicians, there is a strong argument to provide adequate undergraduate urological education to medical students. As Canada's population continues to age, there will be more patients with urological symptoms and conditions presenting to primary care physicians. ${ }^{7,8}$ Currently, there is limited Canadian data on the proportion of patients with urological symptoms and diagnoses presenting to primary care physicians, however data from the United Kingdom suggests that up to $5-10 \%$ of patients present to primary care physicians with issues that are urological in origin. ${ }^{9}$ Therefore, though there is limited data on the burden of urological disease presenting to primary care practitioners in Canada, there is a significant overall prevalence of urological conditions and this is anticipated to increase over time with the aging population.

The goal of the undergraduate medical curriculum is to graduate undifferentiated medical doctors who can recognize and manage common and life-threatening conditions pertaining to all body systems. It is expected that all graduating medical students will successfully complete the Medical Council of Canada Qualifying Examination Part 1 (MCCQE1) prior to commencing their residency. The MCCQE1 is a mandatory high stakes examination that evaluate the preparedness of medical students to approach the 'undifferentiated patient' with multiple presentations, including a number of different urological presentations. In 2018, approximately $40 \%$ of Canadian medical school graduates matched to a Family Medicine residency ${ }^{10}$ and this group of learners will rely heavily on the basic urological knowledge and skills they learned in their undergraduate studies for their entire careers. Despite the need for urological instruction 
and exposure in the undergraduate curriculum, there is currently no literature that assesses the formal undergraduate urological curriculum in Canadian medical schools. The purpose of this study is to inform medical educators and administrators about the current undergraduate urology education landscape in Canada with the goal of using this data to address future curriculum developments in Canadian medical schools. These future curriculum developments may include utilizing a national undergraduate urological curriculum that has already been designed by the Canadian Undergraduate Urology Curriculum Committee (CanUUCC).

\section{Methods}

A structured English electronic survey was administered to the undergraduate urology education directors (UUED) of all 17 Canadian medical schools (both Anglophone and Francophone) via SurveyMonkey. The survey was designed by a urologist with training in medical education research design, using best practices in educational survey design ${ }^{11}$. The survey respondents from Francophone medical schools were all bilingual and did not require a French version of the survey. The survey was sent with instructions for the UUEDs to only report on curricular elements that were under their purview, constituting the formal urological undergraduate curriculum. The survey opened on October 21, 2018 and the last response was collected on December 9,2018. The survey assessed multiple factors, including hours of instruction, urological topics covered in the curriculum, use of standardized patients (SPs) to teach male rectal and genital examinations, amount of urological exposure during clerkship, adequacy of content, and the preparedness of graduating students to diagnose and treat common urological conditions (see Appendix 1 for the entire survey). The Medical Council of Canada Qualifying Examination Part 1 (MCCQE1) medical expert objectives ${ }^{12}$ were primarily used to populate the undergraduate urology topic areas included in the survey and the list of topics was also reviewed by undergraduate urology educators from across Canada (from both Anglophone and Francophone school) from the Canadian Undergraduate Urology Curriculum Committee (CanUUCC) prior to survey distribution.

To determine if the presence of a urology residency program had an effect on the total number of instructional hours, the average total number of hours of urological instruction was compared between schools with a five-year post-graduate urology residency program $(n=12)$ and those without a urology residency program $(n=5)$. Additionally, the mean number of instructional hours was compared between schools where UUEDs perceived their graduating students to be 'somewhat prepared' or 'prepared' to diagnose and treat common urological conditions $(\mathrm{n}=12)$ versus schools were the UUEDs perceived their graduating students to be 'unprepared' for such tasks $(\mathrm{n}=5)$.

\section{Results}

All 17 UUEDs completed the survey, giving a response rate of $100 \%$. There was considerable variation in the duration (mean total duration: $22.5+/-17.2$ [5-75] hours) of urological instruction and timing of when urological topics were taught in the formal urological curriculum 
(Figure 1). Fifteen schools have a structured urology pre-clerkship curriculum, with a mean duration of $9.5+/-6.1$ [2-27] hours of pre-clerkship lectures and 5.6 +/- 6.0 [0-24] hours of preclerkship small group instruction. In clerkship, the mean duration of lectures is $3.8+/-3.9$ [0-15] hours and the mean duration of small group instruction is $3.5+/-5.8$ [0-24] hours. All Canadian schools covered the following five topics at least once in their curriculum: hematuria, lower urinary tract symptoms (LUTS), urinary tract obstruction, urolithiasis and instruction on the male genitourinary examination. Three topics were underrepresented in the curriculum, with the minority of schools reporting it being taught in the formal urological curriculum: erectile dysfunction (29.4\%), uro-trauma (35.3\%) and pediatric urology topics (41.2\%). One school surveyed had a mandatory one-week urology clerkship rotation, while the remaining 16 schools offered a urology selective (median 2 weeks) for students to participate in. In schools that offered the selective, $24.3 \%(5-50 \%)$ of students completed this experience. For urological clinical skills teaching, more than half of schools $(64.7 \%)$ used SPs to teach male rectal and genital examinations. Most UUEDs (64.7\%) believed the curricular time devoted to urology was inadequate (Figure 2) and approximately one third (29.4\%) felt that their graduates were unprepared to diagnose and treat common urological problems (Figure 3). Furthermore, 76.5\% of the UUEDs 'strongly agreed or agreed' that a national urology curriculum would be a useful educational resource at their school (Figure 4).

The comparison of schools with and without a five-year post-graduate urology training program demonstrated the total number of urology instructional hours to be higher in schools with a residency program (mean of 26.4 hours) compared to schools without one (mean of 18.4 hours). Additionally. schools where the UUEDs felt graduating students were either 'somewhat prepared' or 'prepared' to diagnose and treat common urological conditions had more formal urological instructional hours (mean of 26.2 hours) compared to schools where the UUEDs felt graduating students were 'unprepared' (means of 13.6 hours). Given the small sample sizes, we did not have sufficient power to perform inferential statistics to compare groups.

\section{Discussion}

The purpose of this study was to assess the current landscape of urological undergraduate education in Canada under the purview of the UUEDs and to determine whether a formally designed national curriculum would be beneficial to address any educational heterogeneity between programs. It was hypothesized that there would be significant variation in the amount of urological instruction between schools and that students from schools with a formal residency program would have more exposure to the discipline. The results showed that every medical school in Canada had some degree of formal urological content in their existing curricula, but there was extensive variation in the amount and timing of urological instruction and the availability of clinical experiences in Canadian medical schools. On average, the presence of a urology post-graduate training program does translate to more formal urology exposure to undergraduate medical students. This study did not address specific reasons for this, however 
one could hypothesize that schools with a post-graduate training program have more available undergraduate teachers, may have more subspecialists to deliver lectures on a greater number of urology topics and potentially have more influence on decisions regarding the amount of formal urology instruction in the undergraduate curriculum. As would be expected, schools were the UUEDs felt that their graduating students were more prepared had more formal instructional hours in urology on average compared to those schools were the UUEDs felt that their students were unprepared. This trend speaks to the importance of instructional hours on graduating student preparedness, especially in a clinical area with limited exposure in the undergraduate curriculum.

Although there was significant curricular heterogeneity identified in this study, it was reassuring to see some topics areas being universally covered by all schools. Hematuria, LUTS, urinary tract obstruction, urolithiasis and instruction on the male genitourinary examination were taught to all Canadian medical students in the formal urological curriculum. There is significant overlap between these five universally covered topics and the top six urological topics that came out of Kerfoot and Turek educational needs assessment for undergraduate medical students in the United States. ${ }^{13}$ Conversely, the minority of Canadian medical schools were adequately covering erectile dysfunction, uro-trauma and pediatric urology topics, which speaks to a potential curricular gap. Given that the study was assessing the educational activities under the purview of the UUEDs, more study is required to determine if the duration of instructional time in the formal urological curriculum is an appropriate surrogate for the amount of total urological training students are actually receiving, by either urologists or others.

There is concern that urology and the clinical skills that have traditionally been taught by urologists have been de-emphasized in undergraduate medical education over time, leading to potential negative consequences for future physicians and their patients. A recent review of undergraduate urology curricula from around the world paints a concerning picture in regards to the current state of undergraduate urology, with the majority of medical students having no or insufficient clinical exposure in urology and very few schools emphasizing urology clinical skill training and assessment. ${ }^{14}$ Additionally, a survey of forty-one accredited American medical schools found that $48 \%$ of surveyed schools had no urology lectures or coursework in preclerkship and a variable urology clinical experience in clerkship ${ }^{3}$ and a similar survey from the United Kingdom found that $63 \%$ of surveyed schools did not have specific urology content in the core medical school curriculum. ${ }^{2}$ In the Canadian context, Nensi and Chande raised concerns about the lack of quantity and quality of education regarding digital rectal examination (DRE) instruction, with a call for more opportunities for students to obtain the necessary experience performing DREs in medical school. ${ }^{15}$ If undergraduate medical students do not obtain competency in fundamental knowledge and skills by the time they begin residency, it can affect their future clinical confidence and ability to perform the task in future practice. A study of Quebec family medicine residents found that $33 \%$ of survey respondents had never received direct supervision or teaching of a rectal examination and only $25 \%$ received this training in 
medical school. ${ }^{16}$ More than half of the residents, $71 \%$, had issues accurately assessing DRE findings on at least one occasion and $84 \%$ had omitted the examination even when they knew it was indicated. Although most omitted the examination due to patient refusal, approximately $25 \%$ responded they omitted the exam due to lack of confidence, discomfort with doing the examination or relying on their supervisor to do the examination instead of them. Additionally, several Canadian studies on primary care have revealed that there is often uncertainty among primary care providers on determining appropriate therapy and need for referral to a urologist for common urological presentations, such as benign prostatic hyperplasia, prostatitis and hematuria. ${ }^{17,18,19}$ These findings, coupled with the large proportion of new medical graduates entering family practice, reiterate the importance of providing adequate urological instruction during medical school in order to provide a solid foundation for further learning and mastery in residency and clinical practice.

Based on the findings of this study, the majority of UUEDs felt that the amount of urological content in the current curricula was inadequate. Previous Canadian studies assessing the perception of graduating medical students to the adequacy of their undergraduate experience in urology demonstrated over $25 \%$ of students in both Manitoba ${ }^{20}$ and British Columbia ${ }^{21}$ felt the curriculum was inadequate. Given these findings, there is a strong rationale to support the ongoing development of a unified Canadian undergraduate urology curriculum, similar to the American Urological Association's Medical Student Curriculum. ${ }^{22}$ The Canadian Undergraduate Urology Curriculum Committee (CanUUCC) is a national body that has been working since 2011 to create a uniquely Canadian undergraduate urology resource for medical students. Over time, CanUUCC has created a multi-faceted online curriculum with both descriptive PowerPoint presentations and podcasts that covers ten important topics in urology at the level of the undergraduate medical student, including: benign prostatic hyperplasia, prostate cancer, urinary tract infection, hematuria, urinary incontinence, pediatric urology topics, uro-trauma, urolithiasis, erectile dysfunction and scrotal conditions. Additionally, two instructional videos on how to insert a urethral catheter and how to perform a genitourinary examination are provided on the web-based platform. Currently the content is only available in English, but there are plans for French translation in the near future. There are also plans to incorporate self-assessment of knowledge into the platform. CanUUCC's wants to disseminate further awareness of this free online resource nationally, so medical students can easily access reliable information to supplement their urological foundational knowledge. By having CanUUCC available to provide this important resource, medical schools would not have to sacrifice more precious curricular time to provide instruction but could use in-class time to focus on applied cases or on acquisition of hands-on urological clinical exam skills. Importantly, this unified curriculum would also ensure that all medical students across the country have access to a comprehensive and comparable urological educational experience, which currently is not the case in the Canadian context. 


\section{Limitations}

This study has important limitations that have to be kept in mind when making conclusion of the data presented. While this study reviewed formal urological education under the purview of the UUEDs, it did not investigate whether urological topics may have been covered formally or informally by other disciplines, such as obstetrics and gynecology, family medicine, emergency medicine, general surgery and pediatrics. Therefore, the amount of urological content in the overall undergraduate medicine curriculum was likely underestimated by the UUEDs. According to Kerfoot and colleagues, there is insufficient evidence that the urological education students receive from non-urologists is inferior to that taught by urologists for common urological conditions. ${ }^{1}$ Therefore, for those schools with less formalized urological education, students may have in fact received adequate exposure to urological concepts by non-urologists which the UUEDs did not account for. More research is required to answer this important question broadly in Canada, potentially by surveying learners specifically on their urological exposure in their undergraduate curriculum. Additionally, the survey responses by the UUEDs are subject to both selection bias and response bias, which may have skewed the results towards a greater perceived need for more extensive urology education in medical schools compared to non-urologists. Including the perspectives of current medical students and residents in regards to their selfidentified comfort with urological presentations and perspectives of other non-urologists that treat and teach about urological conditions would have strengthened the study. Lastly, the survey question on the overall level of preparedness of graduating medical students to diagnose and treat common urological conditions may have been interpreted in multiple ways by the UUEDs. The definition of 'preparedness' may have been interpreted as the ability of the student to pass the urology questions on the MCCQE1 or the student's ability to be competent in their approach to patients with urological issues as a future first year resident. New medical school graduates would have been the best population to survey in order to answer this question, however this study did not survey new graduates. Results of a pan-Canadian survey of family medicine residents regarding their deficits in urological knowledge and skills have recently been published by Redmond and colleagues ${ }^{23}$ and their findings do echo the concerns of our country's undergraduate urology education leaders regarding the lack of preparedness of our graduates, giving some validation to this study's findings. Nonetheless, despite these limitations, this study provides important data that assesses national trends in undergraduate urological education that have never been published previously and speaks to the value of a formal national urology undergraduate curriculum, such as the one that has been designed and consistently updated by CanUUCC.

\section{Conclusions}

There is significant variability in the content and delivery of formal undergraduate urology education in Canadian medical schools. Although some topic areas are covered universally by all medical schools, undergraduate urology education leaders across Canada are concerned that their 
school's current urology curriculum is insufficient. Supporting an easily-accessible on-line national undergraduate urology curriculum that works in tandem with the formal undergraduate urology curriculum could help bridge this potential curricular gap, with the goal of educating graduating medical students to confidently diagnose and manage a variety of urological patient presentations in their future careers. 


\section{References}

1. Kerfoot B, Price B, Masser A et al. The continued decline of formal urological education of medical students in the United States: Does it matter? J Uro 2006; 175:2243-8.

2. Shah J, Billington R, Manson J et al. Undergraduate urology: A survey of current provisions and guidelines for a core curriculum. BJU Int 2002; 89:327-30.

3. Slaughenhoupt B, Ogunyemi O, Giannopoulos M et al. An update on the current status of medical student urology education in the United States. Urology 2014; 84:743-7.

4. Mishail A, Shahsavari M, Kim J et al. Deficits in urological knowledge among medical students and primary care providers: Potential for impact on urological care. J Urol 2008; 180:2140-7.

5. Miner M. Primary care physician versus urologist: How does their medical management of LUTS associated with BPH differ? Curr Urol Rep 2009; 10:254-60.

6. Kin S, Farrokhyar F, Braga L. Survey on the perception of urology as a specialty by medical students. Can Urol Assoc J. 2016; 10:349-54.

7. Herschorn $\mathrm{S}$, Gajewski J, Schulz J et al. A population-based study of urinary symptoms and incontinence: The Canadian Urinary Bladder Survey." BJU Int 2008; 101:52-8.

8. Rawson N, Saad F. The aging male population and medical care for benign prostatic hyperplasia in Canada. Can Urol Assoc J 2010; 4:123-7.

9. Miah S, Mangera A, Venugopal S et al. The clinical need for undergraduate urology. Clin Teach 2015; 12:353-5.

10. R-1 Data and Reports. Ottawa: Canadian Resident Matching Service. https://www.carms.ca/data-reports/. Accessed May 10, 2019.

11. Gall M, Gall J, Borg W. Educational research: an introduction. Boston: Pearson/Allyn \& Bacon; 2007.

12. Examination Objectives Overview: Medical Expert. Ottawa: Medical Council of Canada. https://mcc.ca/objectives/expert/. Accessed September 3, 2018.

13. Kerfoot B, Turek P. What every graduating medical student should know about urology: the stakeholder viewpoint. Urology 2008; 71:549-53.

14. Sam P, Heermans J, Schmidt C. et al. Current state of urological medical school education: A scoping review. Urology 2019; 123:59-63.

15. Nensi A, Chande N. A survey of digital rectal examination training in Canadian medical schools. Can J Gastroenterol 2012; 26:441-4.

16. Bussières A, Bouchard A, Simanyan D, Drolet S. Family medicine residents' training in knowledge about, and perceptions of digital rectal examination. Can Fam Physician 2017;63: e232-7.

17. Yafi F, Aprikian A, Tanguay S et al. Patients with microscopic and gross hematuria: practice and referral patterns among primary care physicians in a universal health care system. Can Uroll Assoc J 2011; 5:97.

18. Yafi F, Aprikian A, Tanguay S et al. Are men on $5 \alpha$-reductase inhibitors appropriately referred to urology? A survey of primary care physicians. BJU international 2011; 108:1269-1273.

19. Nickel J, Nigro M, Valiquette L et al. Diagnosis and treatment of prostatitis in Canada. Urology 1998; 52:797-802. 
20. Patel P, Nayak J, McGregor T. The value of a core clinical rotation in urology for medical students. Can Urol Assoc J 2015;9(11-12):392-6.

21. Hoag N, Hamidizadeh R, MacNeily A. Undergraduate exposure to urology: Impact of the distributed model of medical education in British Columbia." Can Urol Assoc J 2013; 7:20-5.

22. Cohen S. The AUA curriculum for medical students: Current resources and developments. Curr Urol Rep 2019; 20:86

23. Redmond E, Salim S, Domes T et al. Deficits in knowledge and skills among family medicine residents in Canada. Can Urol Assoc J 2020 [e-pub ahead of print]. 


\section{Figures and Tables}

Fig. 1. Areas of urology covered and timing of delivery in the undergraduate curricula in Canadian medical schools $(n=17)$. DRE: digital rectal exam; GU: genitourinary; LUTS: lower urinary tract symptoms; UTI: urinary tract infection.

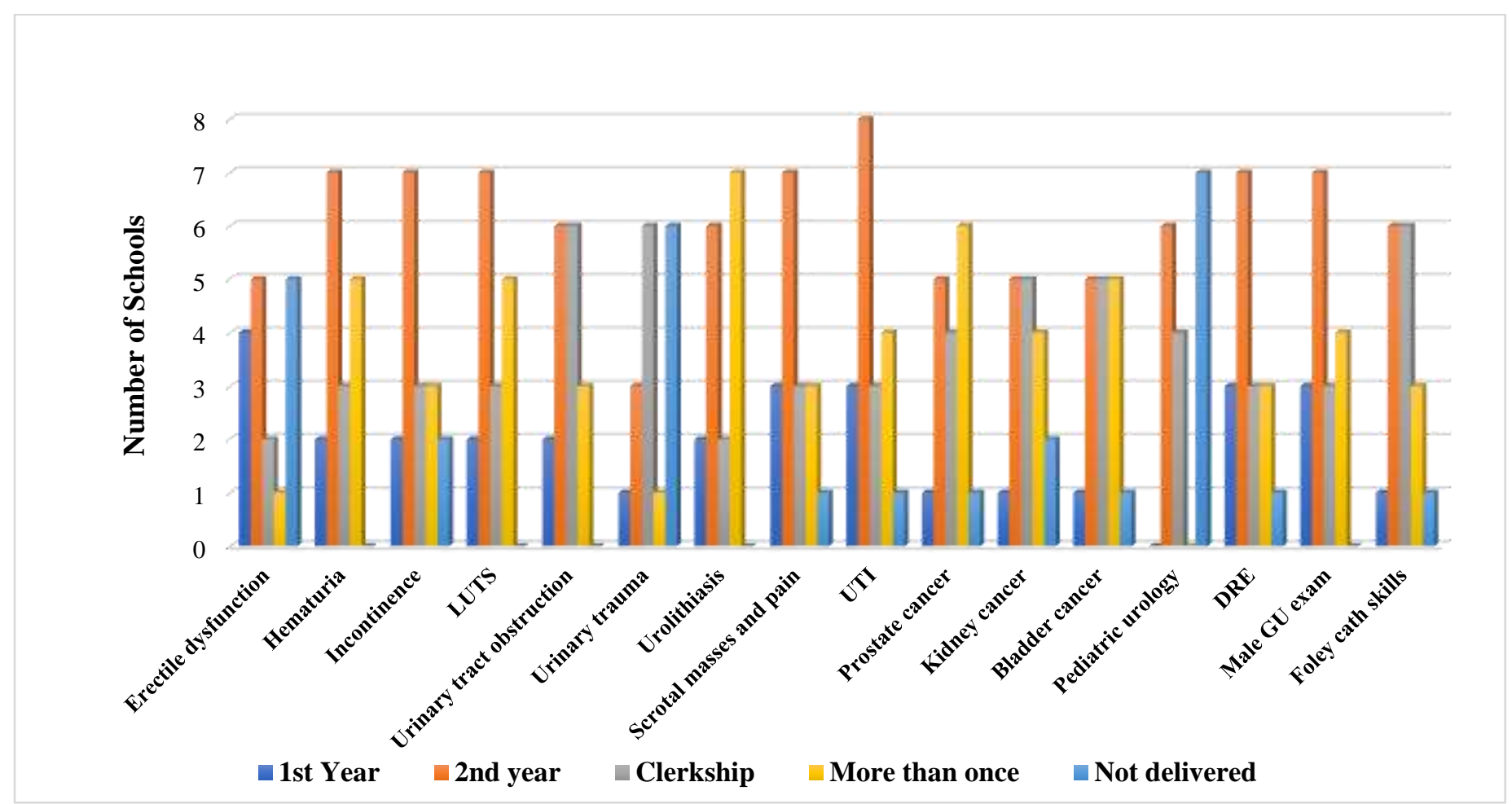


Fig. 2. Response of undergraduate urology program directors (n=17) to the survey question, "Do you feel the amount of urological content in the undergraduate curriculum is adequate at your university?"

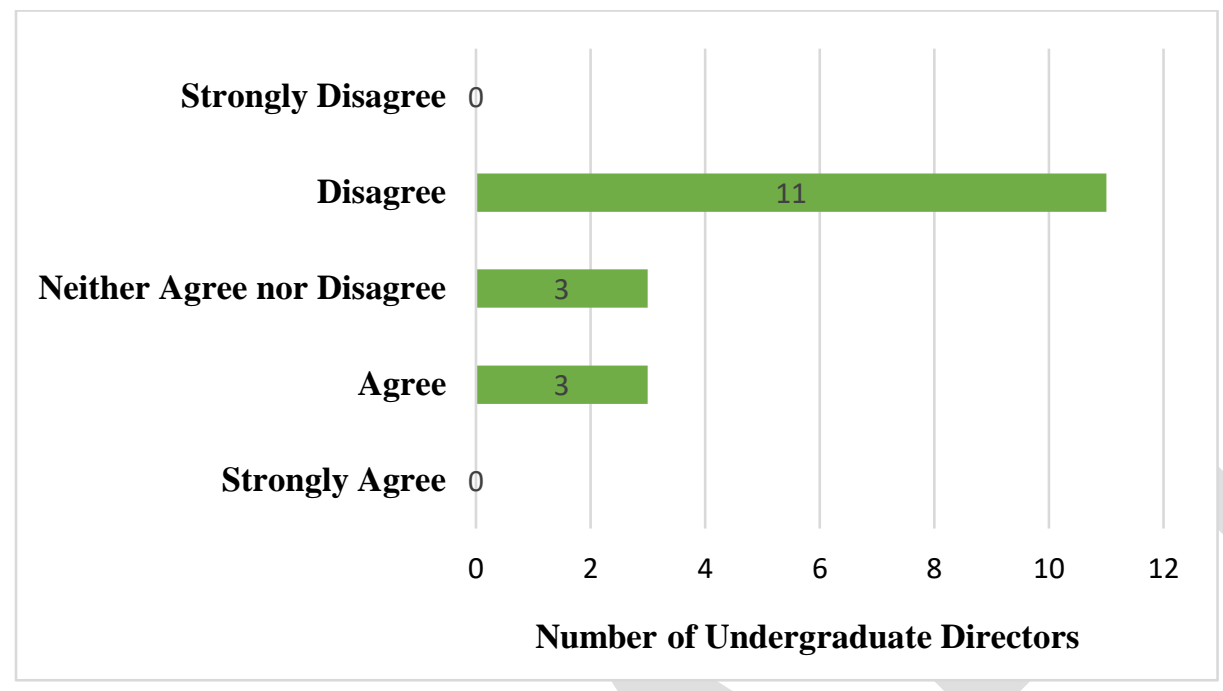

Fig. 3. Response of undergraduate urology program directors $(n=17)$ to the survey question, "Based on your school's overall curriculum, how prepared do you think your average graduating student is to diagnose and treat common urological conditions?"

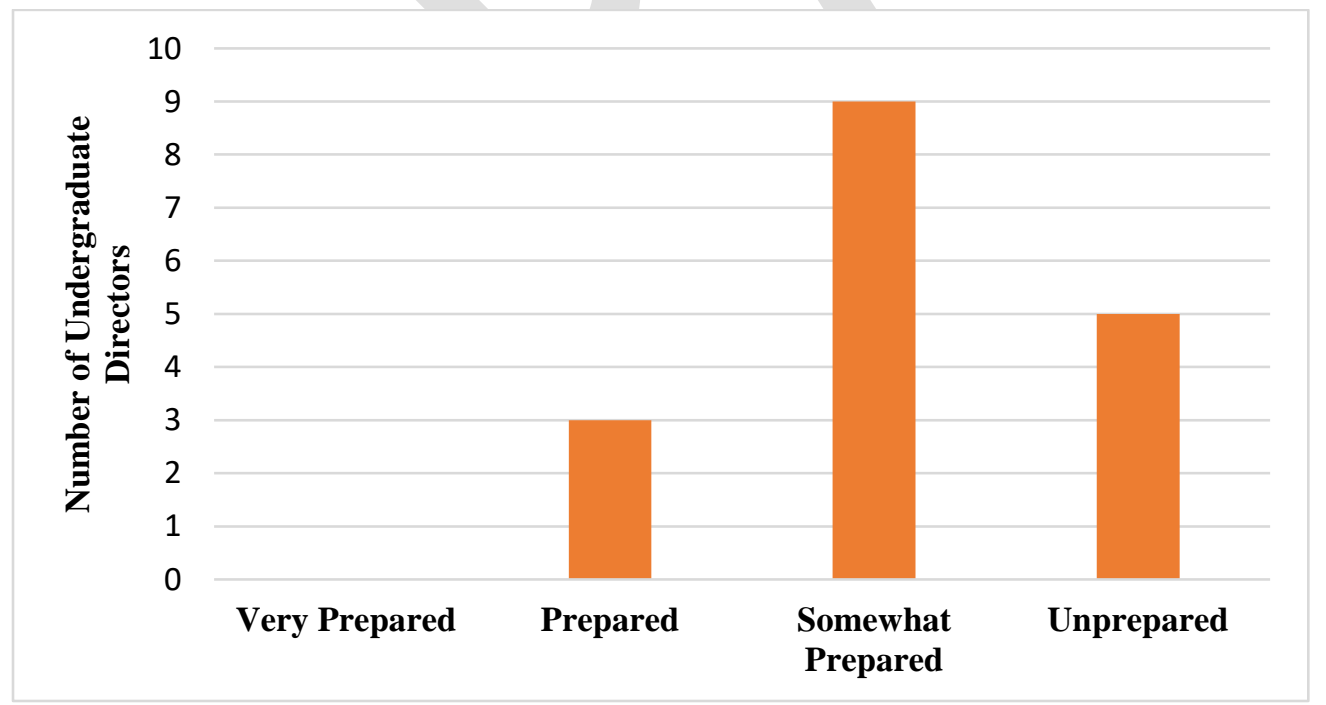


Fig. 4. Response of undergraduate urology program directors $(n=17)$ to the survey question, "Do you feel a nationally developed undergraduate curriculum would be useful at your school?"

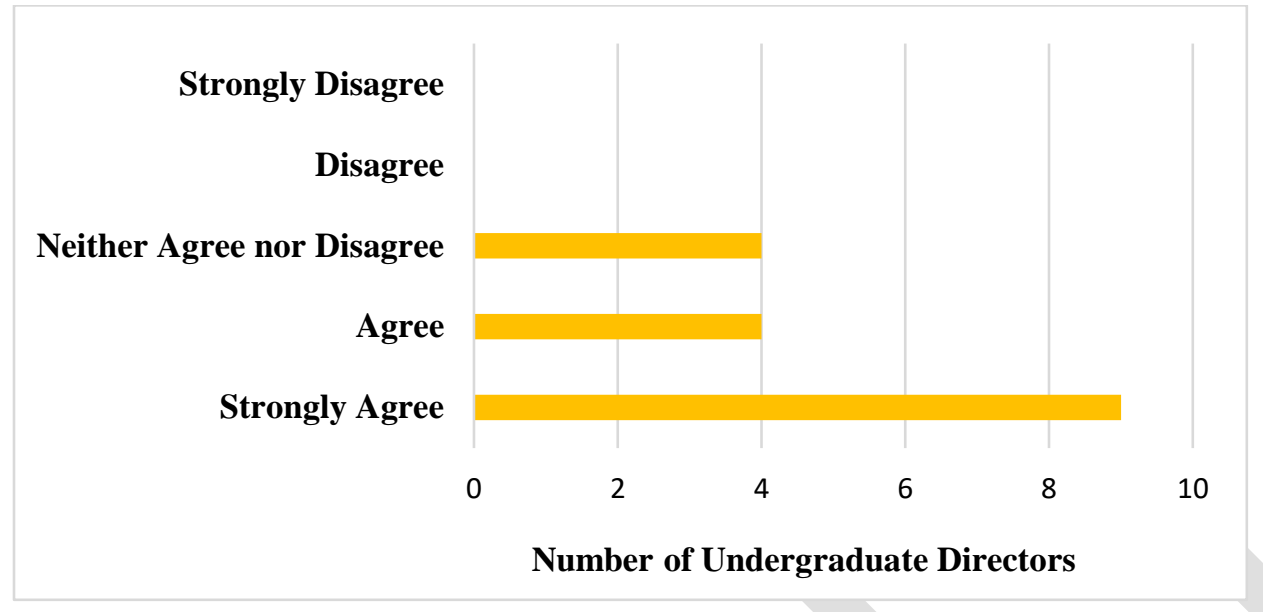




\section{Appendix}

\section{Canadian Undergraduate Urology Survey 2018}

1) What University are you representing?

2) Is there a structured urology pre-clerkship curriculum at your school?

3) Approximately how many hours of urology-specific didactic lectures are given during pre-clerkship (year 1 and 2)?

4) Approximately how many hours of urology-specific small group teaching/non-lecturebased teachings are given in pre-clerkship?

5) Approximately how many hours of urology-specific didactic lectures are given during clerkship (year 3 and 4)?

6) Approximately how many hours of urology-specific small group teaching/non-lecturebased teachings are given in clerkship?

7) When are the following topics formally covered in the curriculum at your school? You can choose more than one response if the topic is covered multiple times. If the topic is not formally covered, choose not covered.

\begin{tabular}{|l|l|l|l|l|}
\hline Topic & First Year & Second Year & Clerkship (Year 3/4) & Not covered \\
\hline Erectile dysfunction & & & & \\
\hline Hematuria & & & & \\
\hline Urinary incontinence & & & & \\
\hline $\begin{array}{l}\text { Lower urinary tract } \\
\text { symptoms }\end{array}$ & & & & \\
\hline $\begin{array}{l}\text { Urinary tract } \\
\text { obstruction }\end{array}$ & & & & \\
\hline Urinary tract injuries & & & & \\
\hline Urolithiasis & & & & \\
\hline $\begin{array}{l}\text { Scrotal masses and } \\
\text { pain }\end{array}$ & & & & \\
\hline $\begin{array}{l}\text { Urinary tract } \\
\text { infections }\end{array}$ & & & & \\
\hline Prostate cancer & & & & \\
\hline Kidney cancer & & & & \\
\hline Bladder cancer & & & & \\
\hline $\begin{array}{l}\text { Pediatric urology } \\
\text { topics }\end{array}$ & & & & \\
\hline Digital rectal exam & & & & \\
\hline
\end{tabular}




\section{Urological undergraduate education in Canada}

\begin{tabular}{|l|l|l|l|l|}
\hline $\begin{array}{l}\text { Male genital } \\
\text { examination }\end{array}$ & & & & \\
\hline $\begin{array}{l}\text { Foley catheterization } \\
\text { skills }\end{array}$ & & & & \\
\hline
\end{tabular}

8) Does your school use standardized patient volunteers to teach male sensitive exams (DRE and male genital examination)?

9) Is urology a mandatory clerkship rotation at your school?

10) If your school has a mandatory urology rotation, how many week(s) is the length of the rotation? Leave at zero if your school doesn't have a mandatory rotation.

11) Is urology an option as a selective in clerkship?

12) If your school has a selective rotation, how many week(s) is the length of this experience? Leave at zero if your school doesn't have a mandatory rotation.

13) If you school has a urology selective rotation, over the last three years approximately what percentage of the total class chooses this option?

14) Do you feel that the amount of urological content in the undergraduate curriculum is adequate at your university?

\begin{tabular}{|l|l|l|l|l|}
\hline Strongly disagree & Disagree & Neither agree or disagree & Agree & Strongly agree \\
\hline
\end{tabular}

15) Based on your school's overall curriculum, how prepared do you think your average graduating medical student is to diagnose and treat common urological conditions?

\begin{tabular}{|l|l|l|l|}
\hline Not prepared & Somewhat prepared & Prepared & Very prepared \\
\hline
\end{tabular}

16) Do you feel a nationally developed undergraduate curriculum would be useful at your school?

\begin{tabular}{|l|l|l|l|l|}
\hline Strongly disagree & Disagree & Neither agree or disagree & Agree & Strongly agree \\
\hline
\end{tabular}

